\title{
Dual biosyntheses of poly[(R)-3-hydroxybutyric acid] and silk protein for the fabrication of biofunctional bioplastic
}

\author{
Keiji Numata ${ }^{1}$ and Yoshiharu Doi ${ }^{2}$
}

This is the first report on dual synthesis of poly[(R)-3-hydroxybutyric acid] (PHB) and protein polymer by recombinant microorganisms for use in the fabrication of a biofunctional PHB-based material hybridized with functional proteins. PHB and recombinant silk protein, a model protein developed in this study, were synthesized by a recombinant Escherichia coli system, and then films of PHB hybridized with the silk protein (PHB/Silk) were prepared. The presence of the silk protein in the amorphous phase of the PHB/Silk film was demonstrated based on wide-angle X-ray diffraction and differential scanning calorimetry measurements, which also revealed the enhanced tensile strength and elongation at break of the PHB/Silk film. The cell adhesion of human mesenchymal stem cells (hMSCs) for the PHB/Silk film increased because of the addition of silk molecules to the film. This might have been because the silk molecules existed in the amorphous phase at the surface of the $\mathrm{PHB} /$ Silk films, and were exposed to hMSCs. The overall results illustrate the potential of this dual synthesis system as a versatile and useful platform method for preparation of biofunctional PHB-based materials, especially for biomedical applications.

Polymer Journal (2011) 43, 642-647; doi:10.1038/pj.2011.27; published online 27 April 2011

Keywords: biomaterial; poly[(R)-3-hydroxybutyric acid]; silk protein

\section{INTRODUCTION}

Poly[(R)-3-hydroxybutyric acid] (PHB), a biological and biodegradable polyester produced by various microorganisms in the natural environment, has attracted much attention in industrial and medical fields because of its eco-friendly properties, including biodegradability, biocompatibility and low cytotoxicity. ${ }^{1-3}$ Medical application of PHB and its copolymer, poly(hydroxyalkanoate) (PHA), has been investigated since the 1990s, and a PHA containing 4-hydroxybutyrate units was provisionally concluded to show higher biocompatibility and in vivo biodegradability than other PHAs. ${ }^{4-7}$ In general, however, PHA materials exhibit few of the biological functions required of modern biomaterials. Many types of surface modifications of PHA films and fibrous mats, such as with collagen, $\mathrm{C}+$ ion, chitosan, gelatin or hyaluronic acid, have therefore been used to enhance the biocompatibility and cell proliferation of PHB and PHA materials. ${ }^{8,9}$ However, these modifications of PHA require several steps and the use of a limited number of substrates. Furthermore, recent advances in biomaterials research for tissue and regenerative engineering have demanded more functional and tailor-made materials, such as functional protein-based materials, for individual medical applications.

Silk proteins have been used successfully in the biomedical field as a suture material for decades, and have also been explored as biomaterials for cell culture and tissue engineering, achieving Food and Drug
Administration approval for such expanded use because of their excellent mechanical properties, and versatility in processing and biocompatibility. ${ }^{10-12}$ In addition, the degradation products of silk proteins by $\alpha$-chymotrypsin composed of $\beta$-sheet structures have been reported to show no significant cytotoxicity to neuron cells in vitro. ${ }^{13-15}$ On the basis of the biocompatibility of silk proteins, numerous silkbased products have been investigated and partially adopted for biomedical treatments, including sutures, scaffolds, films, coating, tubes, microspheres and polyion complexes. ${ }^{11,16}$ In the last decade, remarkable progress has been made in understanding silk genetics, structures and biophysics. ${ }^{17-24}$ Cloning and expression of native and synthetic silks have been achieved in various host systems using synthetic oligonucleotide versions of consensus repeats or variants of these repeats garnered from sequence data from native genes. ${ }^{25-28}$

In this study, dual biosynthesis of both $\mathrm{PHB}$ and silk protein was designed and performed by double transformation into Escherichia coli to add biological functions to PHB-based biomaterials (Figure 1). This dual biosynthesis enabled a single-step preparation of PHB-based materials that exhibited several desirable biological functions. The PHB hybridized with silk protein (PHB/Silk) was characterized with respect to its mechanical, thermal and biological properties. On the basis of the results, the role of silk protein in silk-hybridized PHB materials was discussed and the potential of dual synthesis of PHB and

1Enzyme Research Team, RIKEN Biomass Engineering Program, RIKEN, Saitama, Japan and 2RIKEN Research Cluster for Innovation, RIKEN, Saitama, Japan Correspondence: Dr K Numata, Enzyme Research Team, RIKEN Biomass Engineering Program, RIKEN, 2-1 Hirosawa, Wako-shi, Saitama 351-0198, Japan. E-mail: keiji.numata@riken.jp

Received 31 January 2011; revised 14 March 2011; accepted 15 March 2011; published online 27 April 2011 
functional proteins to create new types of biofunctional materials was evaluated.

\section{EXPERIMENTAL PROCEDURE}

Design and cloning of the recombinant silk sequence and PHB synthase

The spider silk sequence was selected based on the consensus repeat (SGRGGLGGQGAGAAAAAGGAGQGGYGGLGSQGT) derived from the native sequence of the dragline protein MaSpl sequence from the spider Nephila clavipes (Accession P19837). The recombinant silk protein containing six contiguous copies of this repeat was developed through the transfer of cloned inserts to pET-15b, according to our previously published procedures. ${ }^{27,29,30}$ The sequences of the synthetic oligonucleotides encoding the consensus repeat were as follows: Silk-a, 5'-TATGGGTAGAGGCGGGCTG GGTGGCCAGGGTGCAGGTGCGGCTGCGGCTGCCGGCGGTGCCGGCCA AGGTGGCTATGGCGGCCTGGGTTCTCAGGGGG-3'; Silk-b, 5'-GATCCCCC CTGAGAACCCAGGCCGCCATAGCCACCTTGGCCGGCACCGCCGGCAGC CGCAGCCGCACCTGCACCCTGGCCACCCAGCCCGCCTCTACCCA-3'. The restriction sites for NdeI and BamHI are italicized. Both Silk-a and Silk-b are complementary oligonucleotides, which were annealed to form doublestranded DNA. The double-stranded DNAs of the sequences were ligated into pET15b to generate pET15b-Silk to encode a six-histidine tag sequence by DNA ligase (Ligation mix; Nippon Gene, Tokyo, Japan). The PHB biosynthesis genes, that is, the PHB synthase gene $(p h a C)$, the $\beta$-ketothiolase gene $(p h a A)$ and the acetoacetyl-CoA reductase gene ( $p h a B)$, from Ralstonia eutropha H16 were inserted into pBBR1MCS-2. ${ }^{31}$ The plasmid pBBR1MCS2-phbCAB carrying the phaCAB gene from $R$. eutropha $\mathrm{H} 16$ was constructed by introduction of a BamHI fragment containing the phaCAB gene into pBBR1MCS2. The BamHI fragment was cloned and obtained from pGEM-phbCAB constructed by Taguchi et al. ${ }^{32}$ The plasmids used in this study are listed in Table 1. To maintain and select for plasmids within the recombinant E. coli, $100 \mu \mathrm{g}$ of ampicillin and/or $50 \mu \mathrm{g}$ of kanamycin were used as indicated.

\section{Dual synthesis of PHB and silk protein}

These plasmids were introduced into E. coli JM109 (DE3) for production of PHB and silk protein by heat shock transformation (Figure 2). In brief, cells were cultivated in the Luria-Bertani medium supplemented with glucose to a final concentration of $2 \mathrm{mg} \mathrm{ml}^{-1}$, containing an appropriate antibiotic $(100 \mu \mathrm{g}$ of ampicillin and/or $50 \mu \mathrm{g}$ of kanamycin) at $30^{\circ} \mathrm{C}$. Protein expression was induced by the addition of $0.5 \mathrm{~mm}$ isopropyl $\beta$-D-thiogalactopyranoside (IPTG) (Sigma-Aldrich, St Louis, MO, USA) when OD600 nm reached 0.6. After the

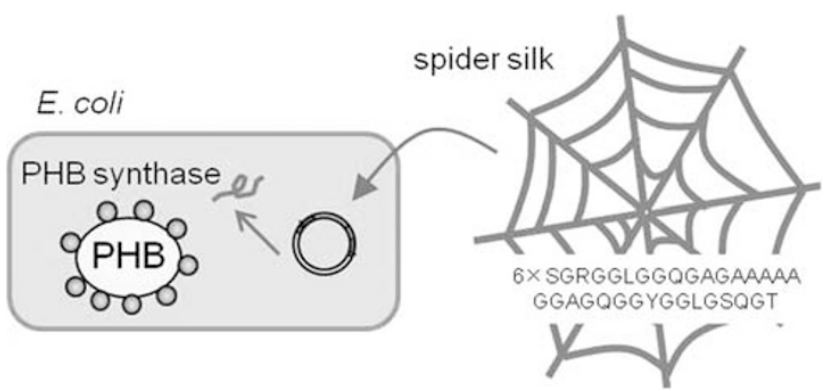

Figure 1 Strategy of this study on dual synthesis of PHB and silk protein. PHB, poly[(R)-3-hydroxybutyric acid]. indicated number of hours of protein expression, cells were harvested by centrifugation at $13000 \mathrm{~g}$. Cell pellets were washed with MilliQ (Millipore, Billerica, MA, USA), followed by centrifugation at $13000 \mathrm{~g}$ at for $30 \mathrm{~min}$. SDS-PAGE was performed using $10-20 \%$ precast Tris- $\mathrm{HCl}$ ready gels (Bio-Rad, Hercules, CA, USA). The soluble-protein fractions were subjected to SDS-PAGE. The gel was stained with Commassie blue (Bio-Rad). Western blotting was performed using a Gel Code $6 \times$ His Protein Tag Stain kit (Pierce, Rockford, IL, USA). Cell pellets were lyophilized and then PHB and/or silk protein were extracted with a mixture of chloroform/HFIP (1,1,1,3,3,3-hexafluoro-2-propanol) (50/50) for $72 \mathrm{~h}$ at room temperature, and then cells were removed by filtration. The extracted samples were purified by precipitation with methanol twice.

\section{Characterization of $\mathrm{PHB}$, silk protein and their complexes}

The PHB and the silk protein were characterized by ${ }^{1} \mathrm{H}$ nuclear magnetic resonance (NMR) spectroscopy, gel-permeation chromatography (GPC), differential scanning calorimetry and wide-angle X-ray diffraction (WAXD). ${ }^{1} \mathrm{H}$ NMR spectra were recorded on JNM-Excalibur270 (Jeol Ltd, Tokyo, Japan) using $\mathrm{CDCl}_{3}$ and HFIP-d2 as solvents. The number-average molecular weight $\left(M_{\mathrm{n}}\right)$, weight-average molecular weight $\left(M_{\mathrm{w}}\right)$ and polydispersity $\left(M_{\mathrm{w}} / M_{\mathrm{n}}\right)$ were measured by a GPC system with polystyrene standards (Shodex Standard SM$105,1.3 \times 10^{3}$ to $\left.3.1 \times 10^{6}\right)$. GPC measurement was performed using a Shimadzu 10A GPC system (Shimadzu Corporation, Kyoto, Japan) with joint columns of Shodex K-806 and K-802 (Showa Denko, Tokyo, Japan) at $40^{\circ} \mathrm{C}$. Chloroform was used as a mobile phase at a flow rate of $0.8 \mathrm{ml} \mathrm{min}^{-1}$, and the sample concentration was set at $1.0 \mathrm{mg} \mathrm{ml}^{-1}$. Shimadzu CLASS-VP software (Shimad$\mathrm{zu}$ Corporation) was used to process the data.

Thick films were initially prepared by conventional solvent-cast techniques from HFIP solutions of PHB and silk protein $\left(10 \mathrm{mg} \mathrm{ml}^{-1}\right)$ using glass petri dishes as a casting surface. Solvent-cast films were inserted between two Teflon sheets with a Teflon sheet $(0.1 \mathrm{~mm}$ thickness) as a spacer and were compression molded on a Mini Test Press (Toyo Seiki Seisaku-sho Ltd, Tokyo, Japan) by heating at $200^{\circ} \mathrm{C}$ for $30 \mathrm{~s}$ under a pressure of $100 \mathrm{~kg} \mathrm{~cm}^{-2}$. The samples were then kept at room temperature $\left(25^{\circ} \mathrm{C}\right)$. The thin films of $0.1-\mathrm{mm}$ thickness were analyzed by differential scanning calorimetry, WAXD and a tensile strength machine.

The glass transition temperature $\left(T_{\mathrm{g}}\right)$, the melting temperature $\left(T_{\mathrm{m}}\right)$, the crystallization temperature $\left(T_{\mathrm{c}}\right)$ and the melting enthalpy $(\Delta H)$ were measured by a differential scanning calorimetry (Pyris 1; Perkin-Elmer, Waltham, MA, USA) equipped with a cooling accessory. The samples $(\sim 3 \mathrm{mg})$ were encapsulated in aluminum pans and heated from -50 to $200^{\circ} \mathrm{C}$ at a rate of

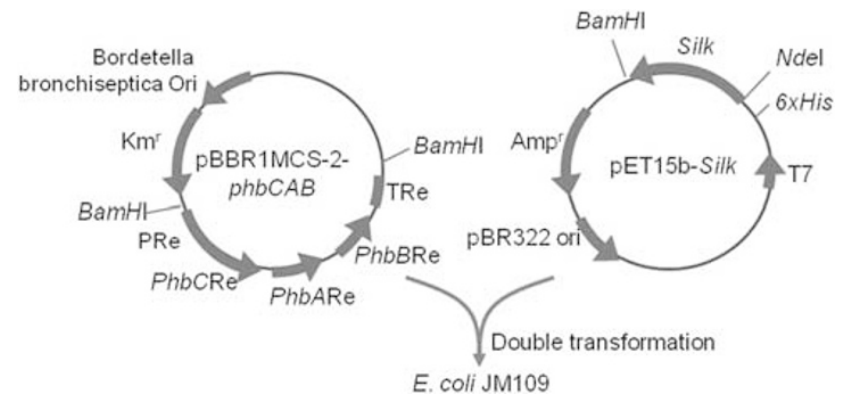

Figure 2 Schematic drawing of recombinant plasmids pBBR1MCS-2phbCAB and pET15b-silk used for dual synthesis of PHB and silk protein. $\mathrm{PHB}$, poly[(R)-3-hydroxybutyric acid].

Table 1 Production of PHB and silk protein by the recombinant $E$. coli JM109 strain using $2 \%$ glucose as a carbon source

\begin{tabular}{|c|c|c|c|c|}
\hline Sample no. & Synthesized product(s) & Plasmids & Dry cell weight, $g I^{-1}$ & PHB content, \% (w/w) \\
\hline 1 & Silk & pET15b-Silk & $1.4 \pm 0.2$ & 0 \\
\hline 2 & PHB & pBBR1MCS-2-phbCAB & $1.4 \pm 0.2$ & $41 \pm 5$ \\
\hline 3 & PHB/Silk & pBBR1MCS-2-phbCAB and pET15b-Silk & $1.5 \pm 0.1$ & $6 \pm 3$ \\
\hline
\end{tabular}

Abbreviations: E. coli, Escherichia coli; $\mathrm{PHB}$, poly[(R)-3-hydroxybutyric acid]. 
$20{ }^{\circ} \mathrm{C} \mathrm{min}^{-1}$, and then maintained at $200{ }^{\circ} \mathrm{C}$ for $1 \mathrm{~min}$. Subsequently, they were quenched to $-100{ }^{\circ} \mathrm{C}$ at a rate of $-200^{\circ} \mathrm{C} \mathrm{min}^{-1}$ and then heated from -100 to $200{ }^{\circ} \mathrm{C}$ at a rate of $20^{\circ} \mathrm{C} \mathrm{min}^{-1}$. The $T_{\mathrm{g}}$ was taken as the midpoint of the change in heat capacity during the second heating.

The WAXD patterns of the films were recorded at $25^{\circ} \mathrm{C}$ on a Rigaku RINT 2500 system (Rigaku Corporation, Tokyo, Japan) using nickel-filtered $\mathrm{Cu} \mathrm{K} \alpha$ radiation $(\lambda=0.154 \mathrm{~nm} ; 40 \mathrm{kV} ; 110 \mathrm{~mA})$ in the $2 \theta$ range from 4 to $60^{\circ} \mathrm{C}$ at a scan speed of $2.0^{\circ} \mathrm{C} \mathrm{min}^{-1}$. Degrees of crystallinity $\left(X_{\mathrm{c}}\right)$ of the polymeric films were calculated from diffracted intensity data according to the method proposed by Vonk. ${ }^{33}$

The tensile strength at break and elongation at break for the same thin films as used in the X-ray analysis were determined using a tensile strength machine (Eztest; Shimadzu Corporation) at a crosshead speed of $10 \mathrm{~mm} \mathrm{~min}^{-1}$. Gauge length and sample width were 5.0 and $2.0 \mathrm{~mm}$, respectively. The average of three measured values was taken for each sample.

\section{Cell culture and cell proliferation}

Human mesenchymal stem cells (hMSCs) were used to investigate cell proliferation on synthesized PHB and silk samples. Cultures were grown to confluence using media consisting of Dulbecco's modified Eagle's medium and $10 \%$ fetal bovine serum, $0.1 \mathrm{~mm}$ nonessential amino acids, $1 \mathrm{ng} \mathrm{ml}^{-1}$ basic

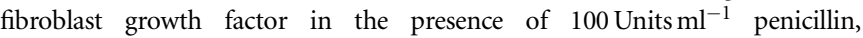
$100 \mu \mathrm{g} \mathrm{ml}^{-1}$ streptomycin and $0.25 \mu \mathrm{g} \mathrm{ml}^{-1}$ fungizone at $37^{\circ} \mathrm{C}$ in a $5 \% \mathrm{CO}_{2}$ incubator. Cell cultures were detached from their substrates using $0.25 \%$ trypsin, and then seeded into 96-well plates (10000 cells per well) coated with PHB and/or silk protein and cultured for 3, 6, 12, 24 or 36 h. After cultivation, media were completely replaced with new media to remove floating cells. Cell proliferation of hMSCs on the polymers was characterized by a standard MTS (3-(4,5-dimethylthiazol-2-yl)-5-(3-carboxymethoxyphenyl)-2-(4-sulfophenyl)$2 \mathrm{H}$-tetrazolium) assay (Promega, Madison, WI, USA) according to the manufacturer's instructions $(n=4)$. The absorbance at $490 \mathrm{~nm}$ of the cell culture was measured after each incubation time. Statistical differences in cell proliferation and cell viability were determined by unpaired $t$-test with a two-tailed distribution and differences were considered statistically significant at $P<0.05$. The data in the cell transfection efficiency and cell viability experiments are expressed as means \pm s.d.

\section{RESULTS AND DISCUSSION}

Dual synthesis of PHB and silk protein

The expression of the silk protein was characterized by SDS-PAGE as shown in Figure 3. The recombinant silk protein showed a band corresponding to a molecular weight of $\sim 27 \mathrm{kDa}$ (Figures $3 \mathrm{a}$ and $\mathrm{b}$ ), which was roughly in accordance with the theoretical molecular weights of $22 \mathrm{kDa}$, considering that silk-based polymers generally do not run true to size on SDS-PAGE gels because of the hydrophobic nature of the protein. ${ }^{25}$ On the basis of the results shown in Figures $3 \mathrm{a}$ and $\mathrm{b}$, an incubation time of 3 or $4 \mathrm{~h}$ was considered optimal to express the silk protein. Therefore, an incubation of $4 \mathrm{~h}$ after the addition of IPTG was used for the expression of silk protein and PHB synthases throughout these experiments. Expression of the PHB synthase was also characterized by SDS-PAGE (Figure 3c), but almost no synthase $(60 \mathrm{kDa})$ was detected because of aggregation of the synthases with PHB granules, according to previous reports. ${ }^{34,35}$ Dual expression of the PHB synthase and silk protein by E. coli JM109 without glucose, which is not capable of synthesizing PHB, was characterized by SDS-PAGE (Figure 4). This result clearly demonstrates that the PHB synthase $(60 \mathrm{kDa})$ and silk protein $(27 \mathrm{kDa})$ were expressed in the present reactions (Figure 4, arrows 1 and 2), at the incubation time of $4 \mathrm{~h}$. The faint bands ( $41 \mathrm{k}$ and $26 \mathrm{kDa}$ ) correspond-

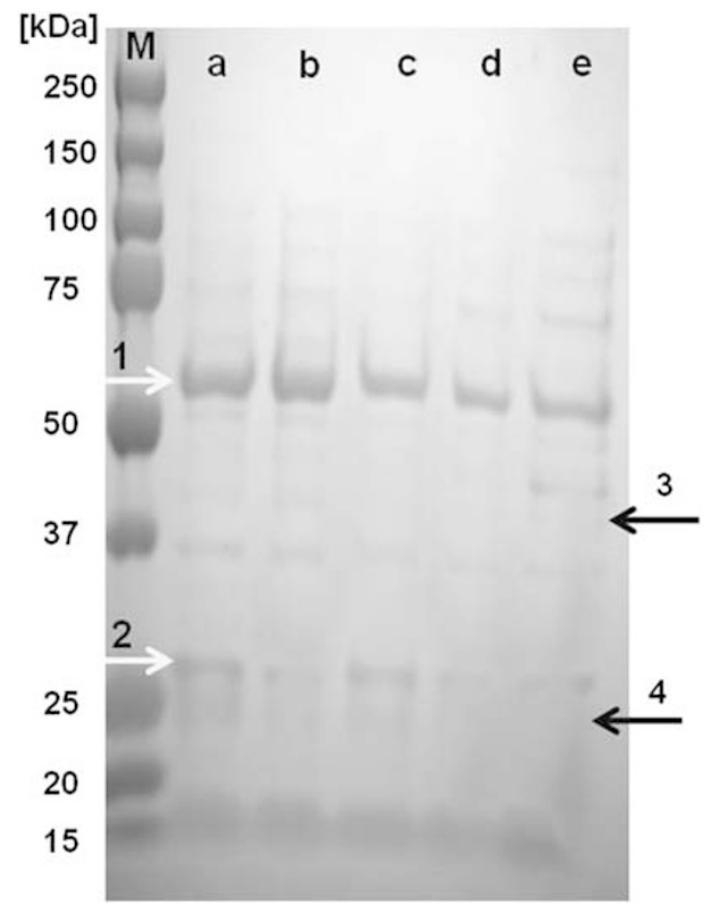

Figure 4 In all, 10-20\% SDS-PAGE of lysates of E. coli JM109 harboring pBBR1MCS-2-phbCABR cultured for (a) 4, (b) 8, (c) 12, (d) 24 or (e) $48 \mathrm{~h}$ without glucose. White arrows denote PHB synthase (PhaC) (1) and silk protein (2), and black arrows show PhaA (3) and PhaB (4), respectively. $\mathrm{M}$, molecular weight size marker; $\mathrm{PHB}$, poly[(R)-3-hydroxybutyric acid].
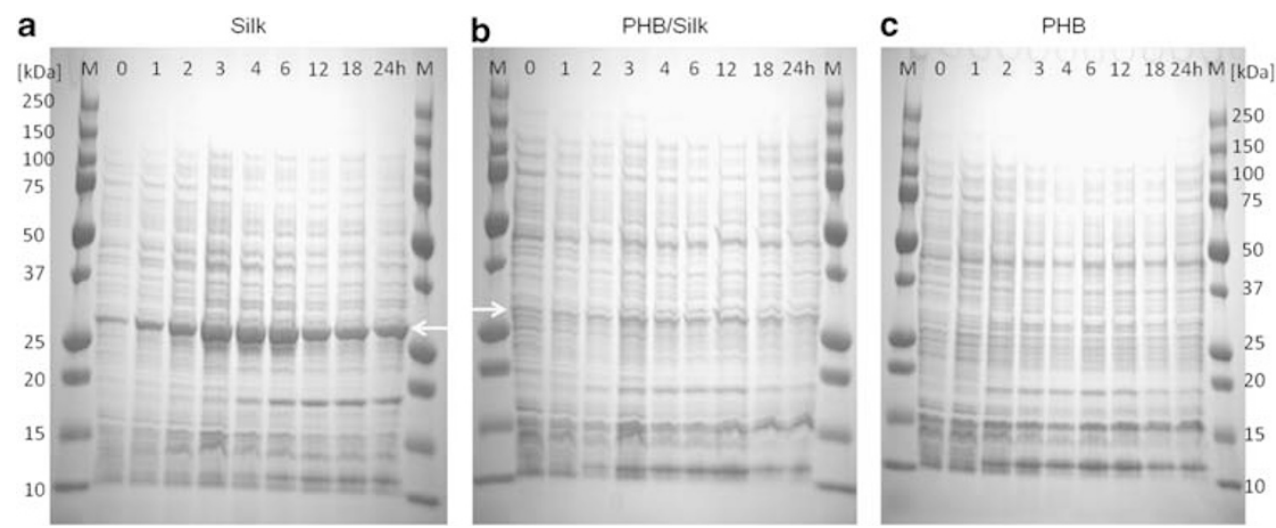

Figure 3 In all, 10-20\% SDS-PAGE of samples during the expression of PHB synthase and silk protein with 2\% glucose before $(0 \mathrm{~h})$ and after addition of $1 \mathrm{~mm}$ IPTG for 1-24h. (a) Silk protein, (b) PHB synthases and silk protein, and (c) PHB synthases. White arrows indicate the expression of silk protein. M, molecular weight size marker; PHB, poly[(R)-3-hydroxybutyric acid]. 
ing to $\beta$-ketothiolase $(\mathrm{PhaA})$ and acetoacetyl-CoA reductase (PhaB) were observed in Figure 4 (arrows 3 and 4). In addition to Figure 4, $\mathrm{PHB}$ production using glucose as a carbon source in E. coli, which contains no PHB biosynthesis genes, confirmed the expression of $\mathrm{PhaA}$ and $\mathrm{PhaB}$. The expressed silk proteins were also confirmed by western blot analysis of histidine tag against the lysates cultured of silk, silk and PHB, as well as PHB (Figure 5). The level of silk protein expressed using recombinant E. coli JM109 harboring both pBBR1MCS-2-phbCAB and pET15b-Silk was significantly lower than that expressed using E. coli JM109 harboring pET15b-Silk, indicating that the expression of $\mathrm{PHB}$ synthase prevented the expression of the silk protein.

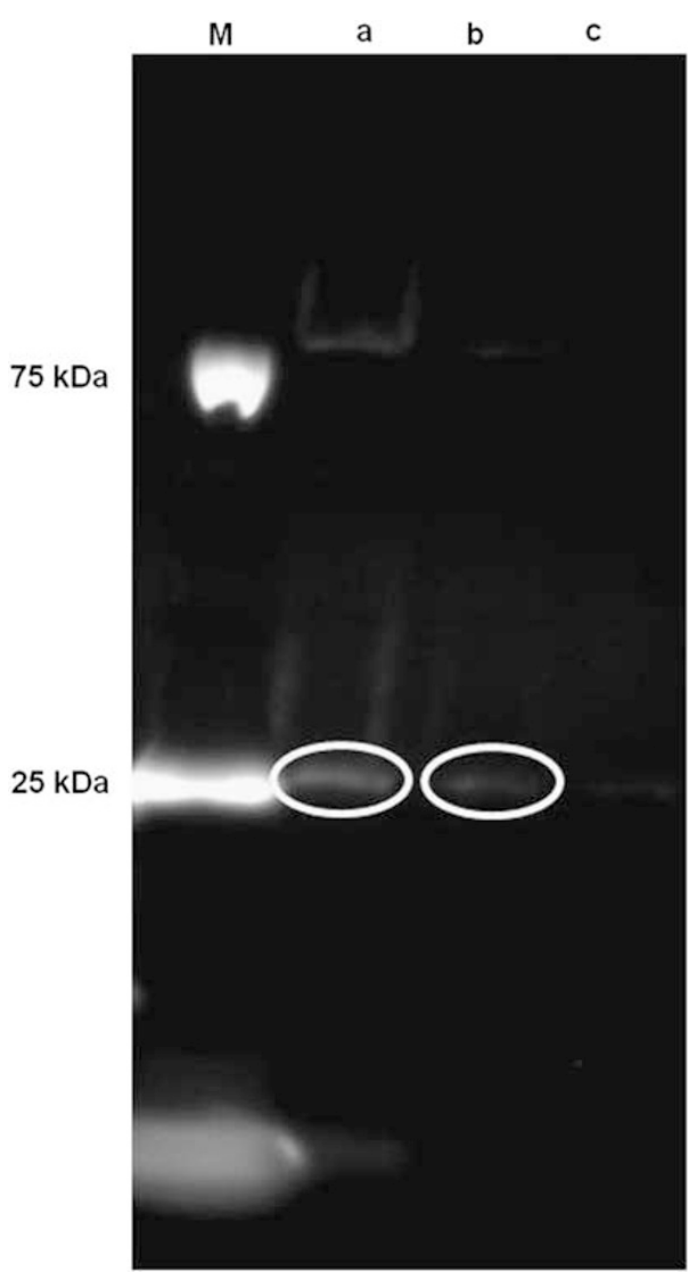

Figure 5 Western blot analysis of a histidine tag against the culture lysates of (a) silk, (b) silk/PHB and (c) PHB for $4 \mathrm{~h}$ after addition of $1 \mathrm{~mm}$ IPTG. $\mathrm{M}$, molecular weight size marker; $\mathrm{PHB}$, poly[(R)-3-hydroxybutyric acid].
Production of PHB by incubation of $4 \mathrm{~h}$ after the addition of IPTG was also characterized quantitatively, as listed in Table 1. Dry cell weights demonstrated almost no difference, whereas PHB contents were significantly different among the samples. The molecular weights and polydispersity index of the PHB synthesized by recombinant E. coli JM109 harboring both pBBR1MCS-2-phbCAB and pET15bSilk and harboring pBBR1MCS-2-phbCAB were determined by GPC (Table 2). The PHB synthesized by recombinant E. coli JM109 harboring pBBR1MCS-2-phbCAB showed an $M_{\mathrm{n}}$ and polydispersity index of $1100000 \mathrm{~g} \mathrm{~mol}^{-1}$ and 1.7, respectively. On the other hand, the molecular weight of the PHB synthesized by recombinant E. coli JM109 harboring both pBBR1MCS-2-phbCAB and pET15b-Silk was $723000 \mathrm{~g} \mathrm{~mol}^{-1}$, which was obviously lower in comparison with the PHB synthesized by recombinant E. coli JM109 harboring pBBR1MCS2-phbCAB. This difference in molecular weight would be caused by the expression of silk protein, which prevented the chain-elongation reaction of the PHB synthase in the microorganism. In addition, the yield of PHB without IPTG induction, namely without silk biosynthesis, was identical to PHB productivity of the E. coli JM109 harboring pBBR1MCS-2-phbCAB (Table 1, sample no. 2). On the basis of the results described above, it was concluded that the expression of the silk protein disturbs $\mathrm{PHB}$ production by $\mathrm{PHB}$ synthase, yielding lower molecular-weight PHB and lower PHB productivity.

\section{NMR analysis of the PHB and silk hybrid}

The PHB synthesized by recombinant E. coli JM109 harboring pBBR1MCS-2-phbCAB and that synthesized by recombinant E. coli JM109 harboring both pBBR1MCS-2-phbCAB and pET15b-Silk were subjected to ${ }^{1} \mathrm{H}$ NMR analysis. ${ }^{1} \mathrm{H}$ NMR spectra of the PHB samples synthesized by recombinant E. coli JM109 harboring pBBR1MCS-2phbCAB (Supplementary Figure S1a) and recombinant E. coli JM109 harboring both pBBR1MCS-2-phbCAB and pET15b-Silk (Supplementary Figure S1b) measured in $\mathrm{CDCl}_{3}$ demonstrated the presence of PHB homopolymers. Moreover, the two spectra in Supplementary Figure S1 were not significantly different, because of the relatively low solubility of the silk protein into chloroform. Hence, the polymer samples dissolved in HFIP-d2 were further characterized by ${ }^{1} \mathrm{H}$ NMR (Figure 6). The spectra of the PHB synthesized by recombinant $E$. coli JM109 harboring pBBR1MCS-2-phbCAB showed no additional peaks into the peaks assigned to $\mathrm{PHB}$, whereas the spectra of the polymers synthesized by recombinant E. coli JM109 harboring both pBBR1MCS-2-phbCAB and pET15b-Silk (Figure 6b) demonstrated additional peaks assigned to poly(amino acid). As shown in Figure 6, the comparison between these spectra revealed that the PHB and silk protein coexisted in the polymers ( $\mathrm{PHB} / \mathrm{Silk}$ ) extracted from the culture of recombinant E. coli JM109 harboring both pBBR1MCS-2phbCAB and pET15b-Silk. The content of the silk protein in the PHB/ Silk hybrid was calculated to be $4.1 \mathrm{~mol} \%$ using the peaks assigned to methine protons of the PHB and silk protein. This silk content, $4.1 \mathrm{~mol} \%$, was enough to influence the mechanical properties and

Table 2 Molecular weights, thermal properties and mechanical properties of PHB and/or silk protein

\begin{tabular}{|c|c|c|c|c|c|c|c|c|}
\hline Sample & Source & $\mathrm{M}_{n}, g_{m o l}^{-1},(P D I)^{\mathrm{a}}$ & $\mathrm{T}_{m},{ }^{\circ} \mathrm{C}$ & $\mathrm{T}_{C},{ }^{\circ} \mathrm{C}$ & $\mathrm{T}_{g},{ }^{\circ} \mathrm{C}$ & Delta $H, J^{-1}$ & Tensile strength, Mpa & Elongation at break, \% \\
\hline PHB/Silk & $\begin{array}{l}\text { E. coli JM109 harboring pET15a-Silk } \\
\text { and pBBR1MCS-2-phbCAB }\end{array}$ & $723000(2.1)$ & 166 & 54 & 7 & 25 & $20 \pm 2$ & $20 \pm 2$ \\
\hline PHB & $\begin{array}{l}\text { E. coli JM109 harboring } \\
\text { pBBR1MCS-2-phbCAB }\end{array}$ & $1100000(1.7)$ & 173 & 49 & 2 & 54 & $16 \pm 2$ & $9 \pm 3$ \\
\hline
\end{tabular}

Abbreviations: E. coli, Escherichia coli; GPC, gel-permeation chromatography; PDI, polydispersity index; PHB, poly[(R)-3-hydroxybutyric acid].

anumber-average molecular weight determined by GPC. 


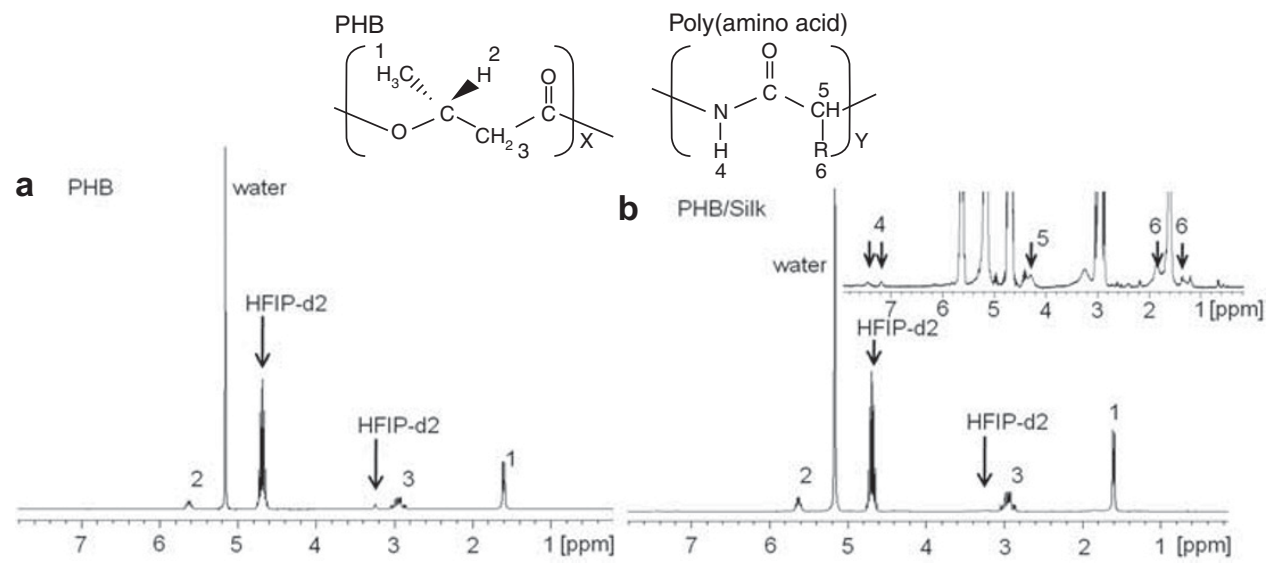

Figure $6{ }^{1} \mathrm{H}$ NMR spectra of (a) PHB and (b) PHB/Silk samples measured in HFIP-d2. HFIP-d2, 1,1,1,3,3,3-hexafluoro-2-propanol-d2; ${ }^{1} \mathrm{H}$ NMR, ${ }^{1} \mathrm{H}$ nuclear magnetic resonance; PHB, poly[( $R)$-3-hydroxybutyric acid].
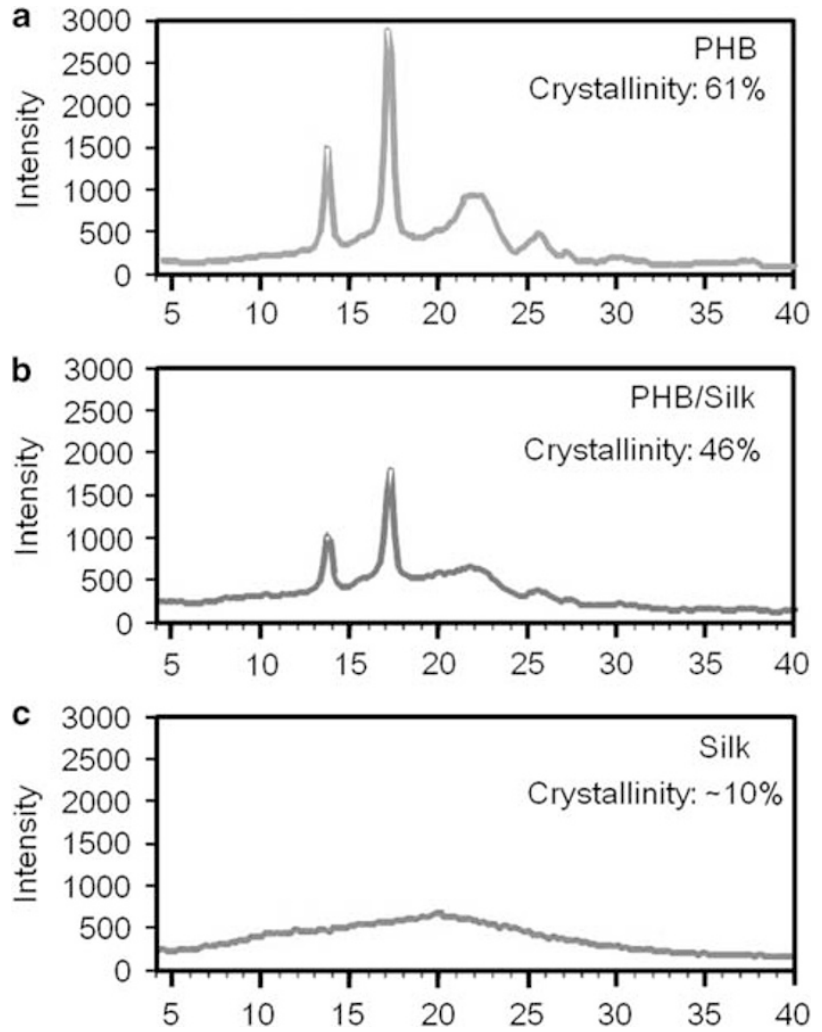

Figure 7 Wide-angle X-ray diffraction (WAXD) patterns of (a) PHB, (b) PHB/ Silk and (c) silk films. Crystallinity was calculated from the diffraction pattern. PHB, poly[(R)-3-hydroxybutyric acid].

biocompatibility of $\mathrm{PHB} / \mathrm{Silk}$ hybrid materials, according to the previous study on poly $[(R)$-3-hydroxybutyrate-co-hydroxyalkanoate $]{ }^{36}$

Effects of the silk protein on the thermal properties, crystalline state and mechanical properties of $\mathrm{PHB} /$ Silk materials

The thermal properties, namely $T_{\mathrm{g}}, T_{\mathrm{m}}, T_{\mathrm{c}}$ and $\Delta H$, of the PHB and $\mathrm{PHB} /$ Silk hybrid films were determined by differential scanning calorimetry and are listed in Table 2 . The presence of the silk protein with PHB decreased $T_{\mathrm{m}}$ as well as $\Delta H$ and increased $T_{\mathrm{c}}$, implying that the presence of silk molecules reduced the crystal sizes and crystallinity of PHB in the PHB/Silk film. To confirm the effects of the silk protein on the crystalline state of the PHB/Silk hybrid, WAXD of the PHB, silk

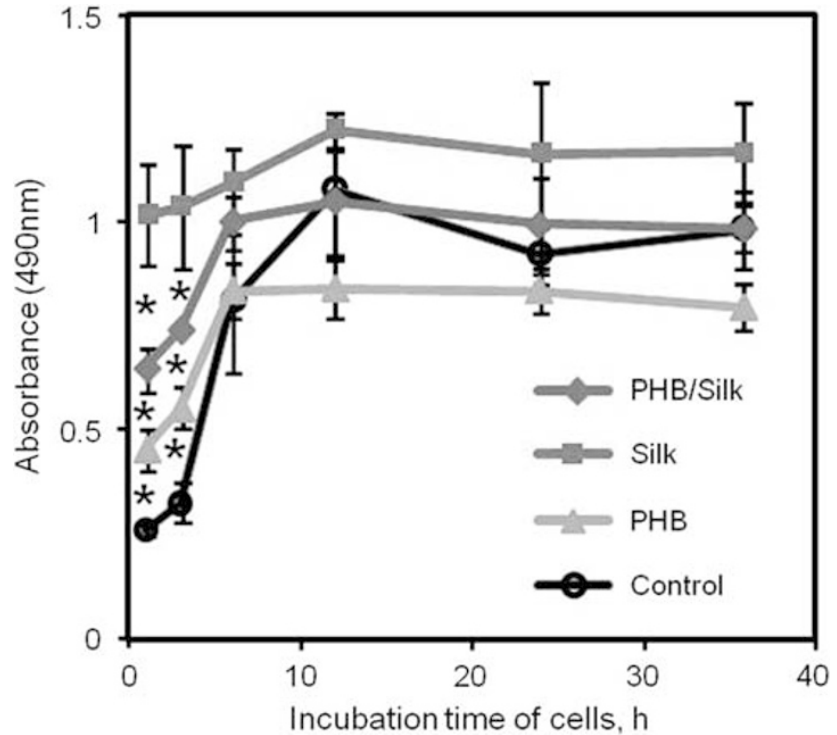

Figure 8 Absorbance at $490 \mathrm{~nm}$ measured using cell cultures after incubation for $3,6,12,24$ or $36 \mathrm{~h}$ on the PHB, silk and PHB/Silk films. Control denotes cell culture plates without any films. *Significant difference between two groups at $P<0.05$. PHB, poly[(R)-3-hydroxybutyric acid].

protein and $\mathrm{PHB} /$ Silk films were performed and $X_{\mathrm{c}}$ of each sample was determined (Figure 7). The diffraction patterns of PHB and PHB/Silk were almost identical, except for the intensity and broad background of the PHB/Silk film. This indicates that PHB lamellar crystals existed in both PHB and PHB/Silk films. The $X_{\mathrm{c}}$ of PHB film (61\%) was significantly higher in comparison with the $X_{\mathrm{c}}$ of the PHB/Silk film (46\%); in addition, the silk film was almost amorphous. Therefore, the presence of silk molecules in PHB materials surely decreased the crystallinity and reduced the crystal sizes based on the area and peaks in the WAXD patterns.

The tensile strength at break and elongation at break of the PHB and $\mathrm{PHB} /$ Silk hybrid films were also determined and are listed in Table 2. The hybridization of silk protein in the PHB/Silk film significantly enhanced tensile strength and elongation at break, which is an important factor for practical use of PHB-based materials as biomaterials. This increase in elongation at break was associated with a decrease in the crystallinity of PHB/Silk due to the hybridization of the silk protein and PHB. The results regarding the crystalline 
state and mechanical properties of PHB/Silk hybrid suggested that the silk molecules were not crystallized but hybridized with amorphous PHB and prevented lamellar crystallization of PHB molecules, leading to higher $T_{\mathrm{c}}$ and higher ductile mechanical properties of PHB/Silk.

\section{Cell adhesion and proliferation}

To evaluate the level of cellular adhesion to the PHB, silk and PHB/Silk films, the proliferation of hMSCs seeded on these films was analyzed using an MTS assay. A 96-well cell culture plate without any films was used as a control. After the removal of floating cells, the absorbance at $490 \mathrm{~nm}\left(\mathrm{~A}_{490}\right)$ related to the numbers of hMSCs attached to the films after incubation for $3,6,12,24$ or $36 \mathrm{~h}$ were measured (Figure 8 ). The $\mathrm{A}_{490}$ of the cell culture incubated on the PHB/Silk, silk and PHB film at 1,3 and $6 \mathrm{~h}$ significantly increased, whereas the $\mathrm{A}_{490}$ of cells adherent to those films from 12 to $36 \mathrm{~h}$ were maintained. This celladhesion behavior indicated that the initial cell-adhesion activity to $\mathrm{PHB} /$ Silk was successfully evaluated from the $\mathrm{A}_{490}$ measured at 1,3 or $6 \mathrm{~h}$, and that its plateau phase started at an incubation time of $\sim 12 \mathrm{~h}$ of all the samples. The silk films showed the highest $\mathrm{A}_{490}$, namely the cell-adhesion activity, whereas the PHB films demonstrated the lowest cell-adhesion activity except for the control. Therefore, the hybridization of the silk protein with $\mathrm{PHB}$ was concluded to increase cell adhesion in comparison with the PHB films. Although the results mentioned above implied the presence of the silk protein in the amorphous phase of the $\mathrm{PHB} /$ Silk film, the additional results on the cell adhesion to the $\mathrm{PHB} /$ Silk films suggest that some silk molecules existed at the surface of the PHB/Silk films and were exposed to hMSCs. The present overall results demonstrate that the dual synthesis of PHB and functional proteins has good potential for the fabrication of biofunctional PHB materials, and more importantly, the hybridization of silk molecules with PHB is a new type of modification for the practical use of PHB materials in biomedical applications.

\section{CONCLUSION}

Dual biosynthesis of the PHB and silk protein, a model protein used in this study, provided a new type of PHB-based material hybridized with silk protein, which showed significantly improved mechanical properties and cell adhesiveness. The presence of the silk protein in the amorphous phase of PHB restrains the crystallinity of the PHB/Silk hybrid. Moreover, the silk molecules may exist in the amorphous phase at the surface of the PHB/Silk film, with the result that the cell adhesion of the film containing silk molecules is enhanced. This present system, dual synthesis of $\mathrm{PHB}$ and functional protein, can serve as a versatile and useful platform method for the preparation of biofunctional PHB-based materials, especially for biomedical applications. This study provides the first example of the hybridization of PHB with functional proteins by this dual synthesis system.

\section{ACKNOWLEDGEMENTS}

This work was supported by a grant for the RIKEN Biomass Engineering Program.

1 Doi, Y. Microbial Polyesters (VCH Publishers, New York, USA, 1990)

2 Doi, Y. \& Steinbüchel, A (eds). in Polyesters / and // Vol. 3 (Wiley-VCH, Weinheim, Germany, 2001).
3 Lenz, R. W. \& Marchessault, R. H. Bacterial polyesters: biosynthesis, biodegradable plastics and biotechnology. Biomacromolecules 6, 1-8 (2005).

4 Martin, D. P., Peoples, O. P., Williams, S. F. \& Zhong, L. H. Nutritional and therapeutic uses of 3-hydroxyalkanoate oligomers. US Patent Appl. 359086 (1999).

5 Martin, D. P. \& Williams, S. F. Medical applications of poly(4-hydroxybutyrate): a strong flexible absorbable biomaterial. Biochem. Eng. J. 16, 97-105 (2003).

6 Martin, D. P. \& Williams, S. F. Medical applications of poly-4-hydroxybutyrate: a strong flexible absorbable biomaterial. Biochem. Eng. J. 16, 97-105 (2003).

7 Williams, S. F. \& Martin, D. P. Therapeutic uses of polymers and oligomers comprising gammahydroxybutyrate. US Patent Appl. 661948 (2000).

8 Chen, G. Q. A microbial polyhydroxyalkanoates (PHA) based bio- and materials industry. Chem. Soc. Rev. 38, 2434-2446 (2009).

9 Chen, G. Q. \& Wu, Q. The application of polyhydroxyalkanoates as tissue engineering materials. Biomaterials 26, 6565-6578 (2005).

10 Altman, G. H., , Diaz, F., Jakuba, C., Calabro, T., Horan, R. L., Chen, J., Lu, H., Richmond, J. \& Kaplan, D. L. Silk-based biomaterials. Biomaterials 24, 401-416 (2003).

11 Numata, K. \& Kaplan, D. L. Silk-based delivery systems of bioactive molecules. Adv. Drug Deliv. Rev. 62, 1497-1508 (2010).

12 Wong Po Foo, C. \& Kaplan, D. L. Genetic engineering of fibrous proteins: spider dragline silk and collagen. Adv. Drug Deliv. Rev. 54, 1131-1143 (2002).

13 Numata, K., Cebe, P. \& Kaplan, D. L. Mechanism of enzymatic degradation of beta-sheet crystals. Biomaterials 31, 2926-2933 (2010).

14 Numata, K. \& Kaplan, D. L. Mechanisms of enzymatic degradation of amyloid beta microfibrils generating nanofilaments and nanospheres related to cytotoxicity. Biochemistry 49, 3254-3260 (2010).

15 Numata, K. \& Kaplan, D. L. Differences in cytotoxicity of beta-sheet peptides originated from silk and amyloid beta. Macromol. Biosci. 11, 60-64 (2011).

16 Omenetto, F. G. \& Kaplan, D. L. New opportunities for an ancient material. Science 329, 528531 (2010).

17 Hinman, M. B. \& Lewis, R. V. Isolation of a clone encoding a second dragline silk fibroin. Nephila clavipes dragline silk is a two-protein fiber. J. Biol. Chem. 267, 19320-19324 (1992).

18 Mita, K., Ichimura, S. \& James, T. C. Highly repetitive structure and its organization of the silk fibroin gene. J. Mol. Evol. 38, 583-592 (1994).

19 Hayashi, C. Y. \& Lewis, R. V. Evidence from flagelliform silk cDNA for the structural basis of elasticity and modular nature of spider silks. J. Mol. Biol. 275, 773-784 (1998).

20 Hayashi, C. Y. \& Lewis, R. V. Molecular architecture and evolution of a modular spider silk protein gene. Science 287, 1477-1479 (2000).

21 Gatesy, J., Hayashi, C., Motriuk, D., Woods, J. \& Lewis, R. Extreme diversity conservation, and convergence, of spider silk fibroin sequences. Science 291, 2603-2605 (2001).

22 Garb, J. E., DiMauro, T., Vo, V. \& Hayashi, C. Y. Silk genes support the single origin of orb webs. Science 312, 1762 (2006).

23 Askarieh, G., , Hedhammar, M., Nordling, K., Saenz, A., Casals, C., Rising, A., Johansson, J. \& Knight, S. D. Self-assembly of spider silk proteins is controlled by a pH-sensitive relay. Nature $465,236-238(2010)$

24 Keten, S., Xu, Z., Ihle, B. \& Buehler, M. J. Nanoconfinement controls stiffness, strength and mechanical toughness of beta-sheet crystals in silk. Nat. Mater. 9, 359-367 (2010).

25 Prince, J. T., McGrath, K. P., DiGirolamo, C. M. \& Kaplan, D. L. Construction, cloning, and expression of synthetic genes encoding spider dragline silk. Biochemistry $\mathbf{3 4}, 10879-10885$ (1995).

26 Huang, J., Valluzzi, R., Bini, E., Vernaglia, B. \& Kaplan, D. L. Cloning, expression, and assembly of sericin-like protein. J. Biol. Chem. 278, 46117-46123 (2003).

27 Numata, K., Subramanian, B., Currie, H. A. \& Kaplan, D. L. Bioengineered silk protein-based gene delivery systems. Biomaterials 30, 5775-5784 (2009).

28 Numata, K., Hamasaki, J., Subramanian, B. \& Kaplan, D. L. Gene delivery mediated by recombinant silk proteins containing cationic and cell binding motifs. J. Control Release 146, 136-143 (2010)

29 Numata, K., Hamasaki, J., Subramanian, B. \& Kaplan, D. L. Gene delivery mediated by recombinant silk proteins containing cationic and cell binding motifs. J. Control Release 146, 136-143 (2010).

30 Numata, K. \& Kaplan, D. L. Silk-based gene carriers with cell membrane destabilizing peptides. Biomacromolecules 11, 3189-3195 (2010).

31 Kovach, M. E., Elzer, P. H., Hill, D. S., Robertson, G. T., Farris, M. A., Roop, R. M. II \& Peterson, K. M. Four new derivatives of the broad-host-range cloning vector pBBR1MCS, carrying different antibiotic-resistance cassettes. Gene 166, 175-176 (1995).

32 Taguchi, S., , Maehara, A., Takase, K., Nakahara, M., Nakamura, H. \& Doi, Y. Analysis of mutational effects of a polyhydroxybutyrate (PHB) polymerase on bacterial PHB accumulation using an in vivo assay system. FEMS Microbiol. Lett. 198, 65-71 (2001).

33 Vonk, C. G. Computerization of rulands X-ray method for determination of crystallinity in polymers. J. Appl. Crystallogr. 6, 148-152 (1973).

34 Peters, V. \& Rehm, B. H. In vivo monitoring of PHA granule formation using GFP-labeled PHA synthases. FEMS Microbiol. Lett. 248, 93-100 (2005).

35 Jurasek, L. \& Marchessault, R. H. Polyhydroxyalkanoate (PHA) granule formation in Ralstonia eutropha cells: a computer simulation. Appl. Microbiol. Biotechnol. 64, 611-617 (2004).

36 Koyama, N. \& Doi, Y. Effects of solid-state structures on the enzymatic degradability of bacterial poly(hydroxyalkanoic acids). Macromolecules 30, 826-832 (1997).

Supplementary Information accompanies the paper on the Polymer Journal website (http://www.nature.com/pj) 